Check for updates

Cite this: Chem. Commun., 2020, 56,8237

Received 18th May 2020,

Accepted 10th June 2020

DOI: $10.1039 / \mathrm{d} 0 \mathrm{cc} 03554 \mathrm{~h}$

rsc.li/chemcomm

\section{Transition metal decorated soft nanomaterials through modular self-assembly of an asymmetric hybrid polyoxometalate $\dagger$}

\author{
Elizabeth Hampson, ${ }^{a}$ Jamie M. Cameron, (D) a Julie A. Watts ${ }^{b}$ and \\ Graham N. Newton (D) *a
}

\begin{abstract}
An asymmetrically functionalised Wells-Dawson organic-inorganic hybrid polyoxometalate has been post-functionalised by $\mathrm{Pt}^{2+}$ coordination, and demonstrates self-assembly into surfacedecorated micellar nanostructures. This multifunctional hybrid material is found to be a redox-active soft nanomaterial and demonstrates a new molecular design strategy with potential for applications in photo- or electro-catalysis.
\end{abstract}

New organic-inorganic hybrid materials, which use molecular design strategies to control their self-assembly into hierarchical structures and fine-tune their chemical properties, have attracted considerable attention in recent years for their wideranging potential applications. ${ }^{1}$ One of the most effective strategies is the use of tuneable molecular 'building blocks' which can confer multiple complimentary organic and inorganic functionalities. Polyoxometalates (POMs) - a class of unique, nanosized, molecular metal-oxide clusters - are particularly attractive in this regard, combining rich photo- and electro-chemical properties with stable, highly modular structures. ${ }^{2}$ In particular, the ability of POMs to covalently incorporate organic groups via rational, post-synthetic modification allows their physicochemical properties to be selectively tuned, ${ }^{3}$ and has facilitated their exploration as novel organic-inorganic amphiphiles (e.g. by incorporating long-chain hydrophobic moieties). ${ }^{4}$ This has led to growing interest in the use of organofunctionalised hybrid-POM species as discrete building blocks with great promise for the construction of unique soft-materials with a range of enhanced, switchable functionalities. ${ }^{4 a, 5}$ The self-assembly of hybrid-POMs into soft nanostructures has also been shown to be dependent on

\footnotetext{
${ }^{a}$ GSK Carbon Neutral Laboratory for Sustainable Chemistry,

University of Nottingham, Nottingham, NG7 2GA, UK.

E-mail: graham.newton@nottingham.ac.uk

${ }^{b}$ Nanoscale and Microscale Research Centre, University of Nottingham,

Nottingham, NG7 2RD, UK

$\dagger$ Electronic supplementary information (ESI) available: Full experimental details and additional NMR, ESI-MS, spectroscopic, light scattering and potentiometric analyses. See DOI: 10.1039/d0cc03554h
}

a number of easily controlled factors (in addition to the design of the POM cluster itself), such as solvent, ${ }^{4 d, e, 6} \mathrm{pH}$, cations, ${ }^{7}$ or coordination of metal ions, ${ }^{6,8}$ all of which open up a number of wide-ranging material design strategies.

One of the outstanding challenges in the field remains the development of multicomponent molecular building blocks into which a range of structure-directing or functional groups can be incorporated. An emerging strategy is the development of asymmetric hybrid-POMs, in which two (or more) distinct organic groups are covalently bound to the POM core. Due to considerable challenges in the synthesis and purification of such compounds however, only a select few examples have been reported to date, ${ }^{9}$ almost all of which are based on the minimally functional $\left[\mathrm{MnMo}_{6} \mathrm{O}_{24}(\mathrm{~L})_{2}\right]^{3-}$ Mn-Anderson cluster. ${ }^{10}$ Recently, our group reported the simple one-pot synthesis of the first stable, bi-functionalised asymmetric hybrid-POM based on the $\left[\mathrm{P}_{2} \mathrm{~W}_{18} \mathrm{O}_{62}\right]^{6-}$ Wells-Dawson cluster. ${ }^{11}$ This new species, $\mathrm{K}_{4}\left(\mathrm{C}_{2} \mathrm{H}_{8} \mathrm{~N}\right)_{2}\left[\mathrm{P}_{2} \mathrm{~W}_{17} \mathrm{O}_{61}\left(\mathrm{P}(\mathrm{O}) \mathrm{C}_{21} \mathrm{H}_{14} \mathrm{~N}_{3}\right)\left(\mathrm{P}(\mathrm{O}) \mathrm{OC}_{24} \mathrm{H}_{41}\right)\right]$ (1) (see Scheme 1), demonstrates unique multifunctionality driven by the inclusion of both aliphatic long-chain alkane and metalchelating terpyridine (TPY) groups, alongside the inherent photo- and redox-activity of the POM core. 1 also shows solvent-dependent self-assembly into low dispersity micellar structures, however, when we attempted to combine this with metal-functionalisation using $\mathrm{Fe}^{2+}$ ions, new dimeric clusters formed which were found to aggregate into smaller, more condensed nanostructures resembling those recently reported by Izzet and Proust, and lacking the distinct shape and hollow interior of the micellar species formed by $1 .^{6,12}$

To maximise the potential of soft materials based on asymmetric hybrid-POMs, it will be necessary to controllably combine the distinct properties of each component, such that the functionality of each sub-unit is fully exploited. Here, we demonstrate the self-assembly of an entirely new type of multifunctional $\mathrm{Pt}^{2+}$-decorated micellar nanostructure based on $\mathrm{Pt}$ complexes of the asymmetric POM building block 1. $\mathrm{Pt}^{2+}$ Polypyridyl complexes are known for their unique luminescent 


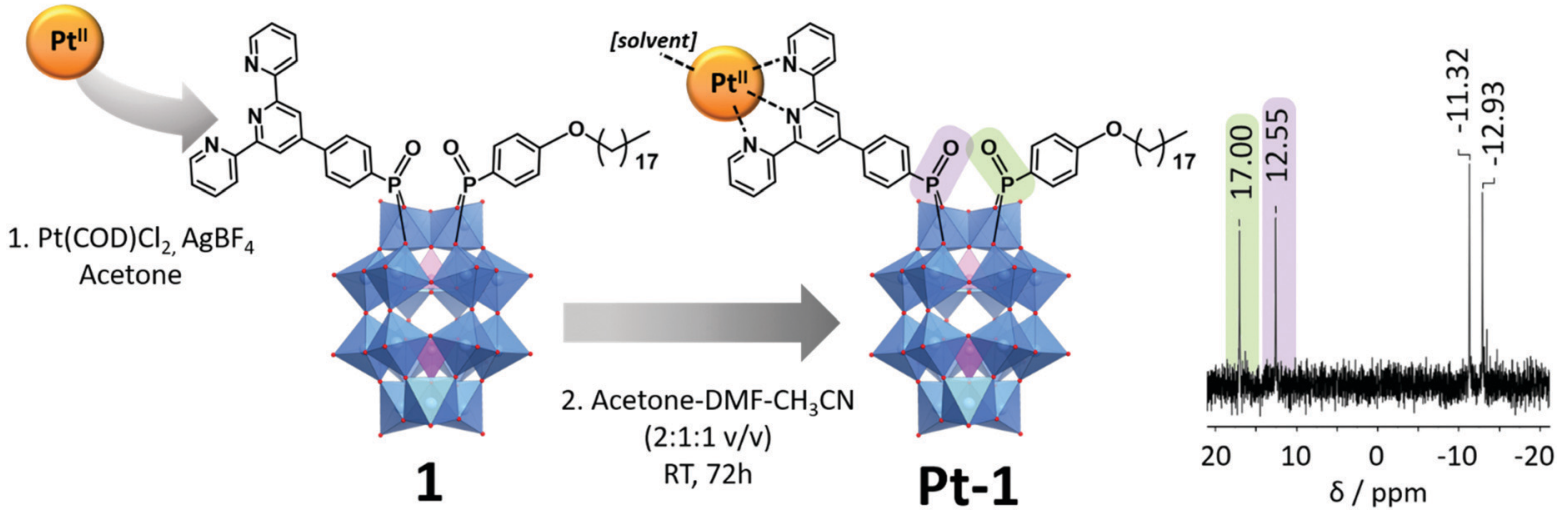

Scheme 1 Preparation of the $\mathrm{Pt}^{2+}$-coordinated hybrid-POM, Pt-1, from the asymmetrically functionalised precursor, 1, showing the ${ }^{31} \mathrm{P}$ NMR spectrum of Pt-1 in DMSO- $d_{6}$. Colour code: blue polyhedra $=\left\{\mathrm{WO}_{6}\right\}$, pink polyhedra $=\left\{\mathrm{PO}_{4}\right\}$, red spheres $=$ oxygen. Cations and solvent molecules are omitted for clarity.

properties, and find application in photocatalysis and DNAintercalation, ${ }^{13}$ whilst the unique supramolecular solventswitchable morphology of the resulting hybrid nanomaterials encodes potential functionality as bespoke catalysts, nanoreactors or molecular-delivery systems. ${ }^{14}$

The Pt-functionalised asymmetric hybrid cluster, $\mathrm{K}_{2}\left(\mathrm{C}_{2} \mathrm{H}_{8} \mathrm{~N}\right)_{3}$ $\left[\mathrm{P}_{2} \mathrm{~W}_{17} \mathrm{O}_{61}\left(\mathrm{P}(\mathrm{O}) \mathrm{C}_{21} \mathrm{H}_{14} \mathrm{~N}_{3} \mathrm{Pt}(\right.\right.$ solv. $\left.\left.)\right)\left(\mathrm{P}(\mathrm{O}) \mathrm{OC}_{24} \mathrm{H}_{41}\right)\right] \cdot n$ DMF (Pt-1), was prepared from the asymmetric hybrid POM, 1, which was synthesised according to our previously reported procedure. ${ }^{11}$ $\left[\mathrm{Pt}(\mathrm{COD}) \mathrm{Cl}_{2}\right](\mathrm{COD}=$ cyclooctadiene $)$ was stirred briefly with two equivalents of $\mathrm{AgBF}_{4}$ in acetone to labilise the $\mathrm{Pt}^{2+}$ complex. The resultant $\mathrm{AgCl}$ was removed by filtration and the Ptcontaining solution was added to a solution of 1 in DMF$\mathrm{CH}_{3} \mathrm{CN}(1: 1 \mathrm{v} / \mathrm{v})$ and stirred at room temperature for $72 \mathrm{~h}$. This resulted in a yellow/orange coloured reaction mixture, which is characteristic of many $\{\mathrm{Pt}(\mathrm{TPY}) \mathrm{L}\}$ complexes. ${ }^{15}$ The reaction mixture was centrifuged to remove any insoluble material, before the solvent was removed in vacuo. The final product was obtained by precipitation from minimal DMF using an excess of diethyl ether. The composition and purity of Pt-1 was confirmed by ${ }^{1} \mathrm{H},{ }^{31} \mathrm{P}$ NMR and FTIR spectroscopies, ESI-MS and elemental (CHN) analysis.

The ${ }^{31} \mathrm{P}$ NMR spectrum of Pt-1 obtained in DMSO- $\mathrm{d}_{6}$ shows signals for both covalently bound ligand groups, with the terpyridine-containing group (P-TPY) and the alkane-group $\left(\mathrm{P}-\mathrm{C}_{18}\right)$ appearing at 12.55 and $17.00 \mathrm{ppm}$ respectively (Scheme 1). Compared to $\mathbf{1}$, the phosphorus nucleus in the P-TPY group is slightly shielded (from $13.40 \mathrm{ppm}$ ) due to the effect of the metal ion coordination, and the $\mathrm{P}^{-\mathrm{C}_{18}}$ phosphorus is very slightly deshielded (from $16.72 \mathrm{ppm}$ ), indicative of some electronic communication between groups, possibly mediated by the POM core (Fig. S3, ESI $\dagger$ ). ${ }^{1} \mathrm{H}$ NMR peaks for the aromatic protons of P-TPY are shifted downfield relative to those of $\mathbf{1}$, suggesting successful coordination of the $\mathrm{Pt}^{2+}$ ion (Fig. S1 and S4, ESI $\dagger) .{ }^{13 a}$ The observation of several signals in the ESI-MS spectra of Pt-1 which closely correspond to the intact cluster additionally confirm successful preparation of the Ptfunctionalised hybrid (Fig. S5 and Table S5, ESI $\dagger$ ).

To explore the multifunctionality of Pt-1 we first studied its redox-activity. Cyclic voltammetry experiments were conducted in DMF on a $0.5 \mathrm{mM}$ solution of Pt-1 with $0.1 \mathrm{M}$ TBA.PF 6 used as the electrolyte. In the potential range of +1.0 to $-2.25 \mathrm{~V}$ ( $v s$. $\left.\mathrm{Fc} / \mathrm{Fc}^{+}\right)$five quasi-reversible redox processes are observed from -0.5 to $-2.25 \mathrm{~V}$ as well as an irreversible oxidation at approximately $+0.5 \mathrm{~V}$ (Fig. 1).

Processes I, II, IV and V are attributed to $\mathrm{W}^{\mathrm{V} / \mathrm{V}}$ redox couples centred on the POM core and are found to be very slightly negatively shifted relative to those observed in $\mathbf{1}$. This indicates some (though very weak) influence on the electronic structure of the POM core by formation of the new Pt-TPY complex. Process III is assigned to TPY/TPY ${ }^{\bullet-}$ redox and has shifted positively due to stabilisation of the TPY radical anion by metal incorporation. ${ }^{16}$ The irreversible oxidation observed at $+0.476 \mathrm{~V}$ can be assigned to the oxidation of $\mathrm{Pt}^{2+}$ to $\mathrm{Pt}^{3+}$, as has been observed for some similar Pt(TPY) complexes, though it should be noted that this remains unresolved in the literature. ${ }^{17}$ Here, we observe that the oxidation only appears once the potential is taken more negative than $c a .-1.8 \mathrm{~V} v s . \mathrm{Fc} / \mathrm{Fc}^{+}$on sequential scanning (Fig. S11, ESI $\dagger$ ).

We then studied the solvent-dependent self-assembly of Pt-1 by dissolving it in a 9:1 (v/v) water-DMF mixture (the compound is first solubilised in DMF, to which was then added

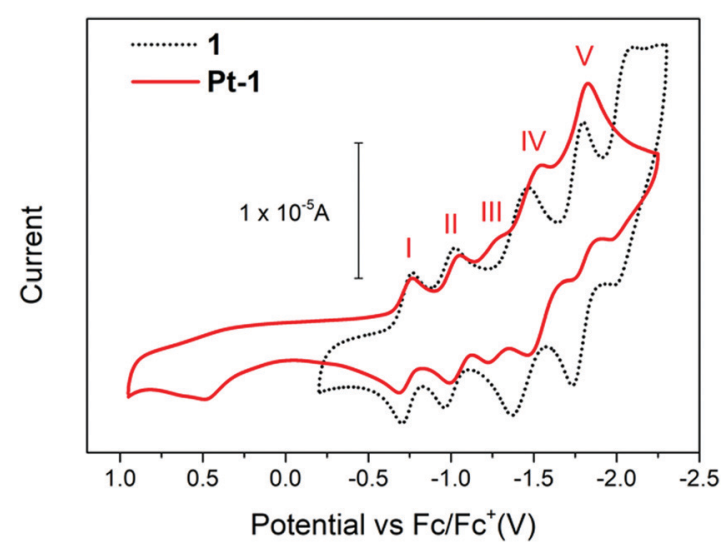

Fig. 1 Overlaid cyclic voltammograms of Pt-1 and precursor asymmetric POM hybrid, 1, collected from a $0.1 \mathrm{M}$ solution of TBA.PF 6 in DMF (see ESI $\dagger$ for details). 

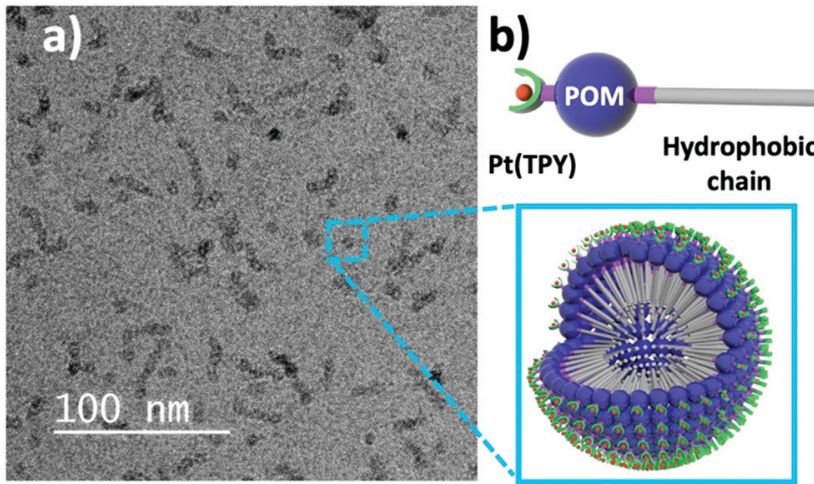

Fig. 2 (a) Cryo-TEM imaging of micellar assemblies of Pt-1 formed in $1.4 \mathrm{mM}$ water-DMF $(9: 1 \mathrm{v} / \mathrm{v})$ solution; (b) the proposed structure of the micellar assemblies.

water) to prepare a $1.4 \mathrm{mM}$ solution. Dynamic Light Scattering (DLS) experiments indicated the formation of assemblies with a hydrodynamic diameter of approximately $6 \mathrm{~nm}$ (Fig. S8, ESI $\dagger$ ). Cryo-TEM analysis of the DLS solution when deposited and frozen on a graphene-oxide and holey carbon-supported $\mathrm{Cu}$ grid showed spherical structures in good agreement with the DLS analysis, with diameters of $6.7 \pm 0.7 \mathrm{~nm}$ (Fig. 2a). Interestingly, these are similar in appearance to the 'worm-like' aggregates reported previously by Izzet et al., however in this case the micellar structure of Pt-1 is still clearly visible. ${ }^{6}$ The spherical assemblies formed by Pt-1 also differ significantly from the randomly shaped aggregates observed in our previous work as a result of the solvent-driven self-assembly of the POM$\mathrm{Fe}^{\mathrm{II}}$-POM dimer derived from $1 .{ }^{11}$ The micelle-favouring 'headtail' polarity of $\mathbf{1}$ is retained upon platinum(II) coordination. In contrast, formation of the dimeric iron(II) complex leads to molecules of ill-defined polarity with restricted capacity to form regular assemblies. The structures of the assemblies formed by Pt-1 constitute a new, and to the best of our knowledge, entirely unique class of surface-decorated micelles (Fig. 2b). This is logical as the Pt-coordinating TPY-sites can only be directed outwards from the hydrophobic core (comprised of the interior-facing $\mathrm{C}_{18}$ chains) as a result of the high angle (approx. $\left.160^{\circ}\right)^{3 b}$ between the two distinct arylphosphonate ligands. This work demonstrates an effective strategy for the preparation of new surfacefunctionalised soft nanomaterials.

In summary, we have successfully postfunctionalised an asymmetrically functionalised Wells-Dawson hybrid POM by the coordination of a platinum(II) centre using a straightforward and broadly applicable synthetic strategy. This work provides an easily accessible and versatile method for the development of new multifunctional hybrid systems with novel supramolecular architectures and tuneable functionalities for new applications as advanced materials.

EH thanks the Low Dimensional Materials and Interfaces Doctoral Training Programme at the University of Nottingham for support. JMC and GNN thank the Leverhulme Trust (RPG2016-442) and the University of Nottingham Propulsion Futures Beacon of Excellence. The authors thank the Engineering and
Physical Sciences Research Council (EPSRC) [EP/L022494/1] and the University of Nottingham for funding TEM instrumentation.

\section{Conflicts of interest}

There are no conflicts to declare.

\section{References}

1 (a) A. B. Descalzo, R. Martínez-Máñez, F. Sancenón, K. Hoffmann and K. Rurack, Angew. Chem., Int. Ed., 2006, 45, 5924-5948; (b) C. Sanchez, B. Julián, P. Belleville and M. Popall, J. Mater. Chem., 2005, 15, 3559-3592; (c) C. Sanchez, G. J. d. A. A. Soler-Illia, F. Ribot, T. Lalot, C. R. Mayer and V. Cabuil, Chem. Mater., 2001, 13, 3061-3083.

2 (a) D.-L. Long, E. Burkholder and L. Cronin, Chem. Soc. Rev., 2007, 36, 105-121; (b) N. I. Gumerova and A. Rompel, Nat. Rev. Chem., 2018, 2, 1-20.

3 (a) A. V. Anyushin, A. Kondinski and T. N. Parac-Vogt, Chem. Soc. Rev., 2020, 49, 382-432; (b) S. Fujimoto, J. M. Cameron, R.-J. Wei, K. Kastner, D. Robinson, V. Sans, G. N. Newton and H. Oshio, Inorg. Chem., 2017, 56, 12169-12177; (c) L. E. VanGelder, B. E. Petel, O. Nachtigall, G. Martinez, W. W. Brennessel and E. M. Matson, ChemSusChem, 2018, 11, 4139-4149; (d) A. J. Kibler, C. Martín, J. M. Cameron, A. Rogalska, J. Dupont, D. A. Walsh and G. N. Newton, Eur. J. Inorg. Chem., 2019, 456-460.

4 (a) D. Li, P. Yin and T. Liu, Dalton Trans., 2012, 41, 2853-2861; (b) J. Zhang, Y.-F. Song, L. Cronin and T. Liu, J. Am. Chem. Soc., 2008, 130, 14408-14409; (c) S. Landsmann, C. Lizandara-Pueyo and S. Polarz, J. Am. Chem. Soc., 2010, 132, 5315-5321; (d) K. Kastner, A. J. Kibler, E. Karjalainen, J. A. Fernandes, V. Sans and G. N. Newton, J. Mater. Chem. A, 2017, 5, 11577-11581; (e) S. Amin, J. M. Cameron, J. A. Watts, D. A. Walsh, V. Sans and G. N. Newton, Mol. Syst. Des. Eng., 2019, 4, 995-999.

5 (a) J. Xu, H. Volfova, R. J. Mulder, L. Goerigk, G. Bryant, E. Riedle and C. Ritchie, J. Am. Chem. Soc., 2018, 140, 10482-10487; (b) D. J. Wales, Q. Cao, K. Kastner, E. Karjalainen, G. N. Newton and V. Sans, Adv. Mater., 2018, 30, 1800159; (c) A. Parrot, A. Bernard, A. Jacquart, S. A. Serapian, C. Bo, E. Derat, O. Oms, A. Dolbecq, A. Proust, R. Métivier, P. Mialane and G. Izzet, Angew. Chem., Int. Ed., 2017, 56, 4872-4876.

6 M. Piot, B. Abécassis, D. Brouri, C. Troufflard, A. Proust and G. Izzet, Proc. Natl. Acad. Sci. U. S. A., 2018, 115, 8895-8900.

7 (a) D. Li, J. Song, P. Yin, S. Simotwo, A. J. Bassler, Y. Aung, J. E. Roberts, K. I. Hardcastle, C. L. Hill and T. Liu, J. Am. Chem. Soc., 2011, 133, 14010-14016; (b) P. Yin, C. P. Pradeep, B. Zhang, F.-Y. Li, C. Lydon, M. H. Rosnes, D. Li, E. Bitterlich, L. Xu, L. Cronin and T. Liu, Chem. - Eur. J., 2012, 18, 8157-8162.

8 P. Yin, T. Li, R. S. Forgan, C. Lydon, X. Zuo, Z. N. Zheng, B. Lee, D. Long, L. Cronin and T. Liu, J. Am. Chem. Soc., 2013, 135, 13425-13432.

9 (a) K. Micoine, M. Malacria, E. Lacôte, S. Thorimbert and B. Hasenknopf, Eur. J. Inorg. Chem., 2013, 1737-1741; (b) A. Saad, O. Oms, A. Dolbecq, C. Menet, R. Dessapt, H. Serier-Brault, E. Allard, K. Baczko and P. Mialane, Chem. Commun., 2015, 51, 16088-16091; (c) Y.-F. Song, N. McMillan, D.-L. Long, S. Kane, J. Malm, M. O. Riehle, C. P. Pradeep, N. Gadegaard and L. Cronin, J. Am. Chem. Soc., 2009, 131, 1340-1341.

10 (a) Y.-F. Song, D.-L. Long, S. E. Kelly and L. Cronin, Inorg. Chem., 2008, 47, 9137-9139; (b) C. Yvon, A. Macdonell, S. Buchwald, A. J. Surman, N. Follet, J. Alex, D.-L. Long and L. Cronin, Chem. Sci., 2013, 4, 3810-3817; (c) C. Yvon, A. J. Surman, M. Hutin, J. Alex, B. O. Smith, D. L. Long and L. Cronin, Angew. Chem., Int. Ed., 2014, 53, 3336-3341; (d) A. Macdonell, N. A. B. Johnson, A. J. Surman and L. Cronin, J. Am. Chem. Soc., 2015, 137, 5662-5665.

11 E. Hampson, J. M. Cameron, S. Amin, J. Kyo, J. A. Watts, H. Oshio and G. N. Newton, Angew. Chem., Int. Ed., 2019, 58, 18281-18285.

12 G. Izzet, B. Abécassis, D. Brouri, M. Piot, B. Matt, S. A. Serapian, C. Bo and A. Proust, J. Am. Chem. Soc., 2016, 138, 5093-5099.

13 (a) I. Eryazici, C. N. Moorefield and G. R. Newkome, Chem. Rev., 2008, 108, 1834-1895; (b) D. K. Crites, C. T. Cunningham and D. R. McMillin, Inorg. Chim. Acta, 1998, 273, 346-353; (c) S. D. Cummings, Coord. Chem. 
Rev., 2009, 253, 1495-1516; (d) K. Sakai and H. Ozawa, Coord. Chem. Rev., 2007, 251, 2753-2766.

14 (a) K. Dong, Q. Sun, Y. Tang, C. Shan, B. Aguila, S. Wang, X. Meng, S. Ma and F.-S. Xiao, Nat. Commun., 2019, 10, 3059; (b) Q.-Q. Wang, S. Gonell, S. H. A. M. Leenders, M. Dürr, I. Ivanović-Burmazović and J. N. H. Reek, Nat. Chem., 2016, 8, 225-230; (c) P. Zhang, J. Wang, H. Chen, L. Zhao, B. Chen, C. Chu, H. Liu, Z. Qin, J. Liu, Y. Tan, X. Chen and G. Liu, J. Am. Chem. Soc., 2018, 140, 14980-14989.

15 J. A. Bailey, M. G. Hill, R. E. Marsh, V. M. Miskowski, W. P. Schaefer and H. B. Gray, Inorg. Chem., 1995, 34, 4591-4599.
16 (a) Q.-Z. Yang, L.-Z. Wu, Z.-X. Wu, L.-P. Zhang and C.-H. Tung, Inorg. Chem., 2002, 41, 5653-5655; (b) M. G. Hill, J. A. Bailey, V. M. Miskowski and H. B. Gray, Inorg. Chem., 1996, 35, 4585-4590.

17 (a) E. Sakuda, A. Funahashi and N. Kitamura, Inorg. Chem., 2006, 45, 10670-10677; (b) G.-J. Zhang, X. Gan, Q.-Q. Xu, Y. Chen, X.-J. Zhao, B. Qin, X.-J. Lv, S.-W. Lai, W.-F. Fu and C.-M. Che, Dalton Trans., 2012, 41, 8421-8429; (c) A. Maroń, K. Czerwińska, B. Machura, L. Raposo, C. Roma-Rodrigues, A. R. Fernandes, J. G. Małecki, A. Szlapa-Kula, S. Kula and S. Krompiec, Dalton Trans., 2018, 47, 6444-6463. 